Psychological

Evaluation

\title{
Digital phenotyping and personality disorders: A necessary relationship in the digital age
}

\author{
Lucas de Francisco Carvalho ${ }^{1}$ \\ iD http://orcid.org/0000-0002-3274-9724 \\ Giselle Pianowski ${ }^{1}$ \\ iD https://orcid.org/0000-0003-4400-7151
}

To cite this paper: Carvalho, L. F., Pianowski, G. (2019). Digital phenotyping and personality disorders: A necessary relationship in the digital age. Psicologia: Teoria e Prática, 21(2), 122-133. doi:10.5935/1980-6906/psicologia.v21n2p122-133

Submission: $28 / 05 / 2018$

Acceptance: $15 / 04 / 2019$

(cc)BY

Todo o conteúdo de Psicologia: Teoria e Prática está licenciado sob Licença Creative Commons CC - By 3.0

1 University of São Francisco, São Paulo, SP, Brazil. 


\begin{abstract}
Digital phenotyping refers to the in-situ quantification of the human phenotype using data from personal digital devices. We argue in favor of using digital phenotyping for mental health, particularly to the personality disorders (PD).We undertake a literature review to ground three main issues, applications, implications, and challenges in harnessing digital phenotyping for PD. The literature presents an amount of studies showing that the PD field can benefit from digital phenotyping. We discuss some key points supporting the envisioned advances in applying the digital phenotyping to PD, such as improvements on assessment, research, PD taxonomy, and, ultimately, on interventions. Despite the prospect progress with this integration, we have discussed many challenges that need to be overcome. While overcoming the challenges, we expect greater practical impact as a result of applying digital phenotyping to PD from professional, patient and community perspectives. The main expectation is to support psychiatric models on prediction over emergency.
\end{abstract}

Keywords: Personality disorders; Mobile Health; mhealth; eHealth; digital phenotype.

\title{
FENOTIPAGEM DIGITAL E TRANSTORNOS DA PERSONALIDADE: UMA RELAÇÃO NECESSÁRIA NA ERA DIGITAL
}

\begin{abstract}
Resumo
O digital phenotyping refere-se à quantificação in-situ do fenótipo humano, usando dados pessoais de dispositivos digitais. Argumenta-se a favor da utilização de digital phenotyping na saúde mental, particularmente nos Transtornos da Personalidade (TP). Foi realizada uma revisão para fundamentar três principais questões, aplicações, implicações e desafios no aproveitamento do digital phenotyping em TPs. A literatura apresenta uma variedade de estudos apontando que a área dos TPs pode se beneficiar do digital phenotyping. Pontos-chave são discutidos, suportando os avanços previstos na aplicação do digital phenotyping aos TPs, como melhorias na avaliação, pesquisa, taxonomia e, finalmente, nas intervenções. Apesar da perspectiva de progresso com esta integração, são discutidos desafios a serem superados. Enquanto superam-se os desafios, espera-se um maior impacto prático da aplicação do digital phenotyping aos TPs nas perspectivas dos profissionais, dos pacientes e da comunidade. A principal expectativa é apoiar os modelos psiquiátricos na prevenção de emergências.

Palavras-chave: transtornos da personalidade; mobile health; mhealth; eHealth; digital phenotype.
\end{abstract}




\title{
FENOTIPADO DIGITAL Y TRASTORNOS DE LA PERSONALIDAD: UNA RELACIÓN NECESARIA EN LA ERA DIGITAL
}

\begin{abstract}
Resumen
El fenotipado digital (FD) se refiere a cuantificación in situ del fenotipo humano utilizando datos de dispositivos digitales. Discutimos a favor de usar FD para salud mental, particularmente los trastornos de la personalidad (TP). Llevamos a cabo una revisión de la literatura para fundamentar principales problemas, aplicaciones, implicaciones y desafíos para aprovechar el FD para TP. La literatura presenta una cantidad de estudios que muestran que el campo de TP puede beneficiarse del FD. Discutimos algunos puntos que respaldan los avances previstos en la aplicación del FD a TP, mejoras en la evaluación, investigación, taxonomía de TP y intervenciones. A pesar del posible progreso con esta integración, discutimos muchos desafíos que deben superarse. Mientras eso, esperamos un mayor impacto práctico como resultado de la aplicación de FD, desde perspectivas profesionales, pacientes y de la comunidad. La principal expectativa es apoyar los modelos psiquiátricos en la predicción sobre la emergencia.

Palabras clave: Desorden de personalidad; Salud móvil; mhealth; eSalud; fenotipo digital.
\end{abstract}

\section{Introduction}

We have come to a moment of the digital age marked not only by high-level digital technology, but also by a technological development with a daily presence never seen before. The direct impact of this envelopment between technology and people can be readily observed in the health sciences, on the use of virtual reality, global positioning system (GPS), robotic, and even nanotechnology for certain medical conditions. New areas can emerge everyday provided that the technological advances allow its development and establishment. This is the case of the emerging field, called digital phenotyping.

Indeed, the first name assigned to the group of information derived from the interaction between humans and technology was digital phenotype (Jain, Powers, Hawkins, \& Brownstein, 2015). This concept refers to how "an individual's interaction with digital technologies affects the full spectrum of human disease from diagnosis, to treatment, to chronic disease management" (Jain et al., 2015, p. 462). In other words, digital phenotype is the amount of health-related data someone 
leave through the interaction with technology (Wiederhold, 2016). According to the authors who first glimpsed the term (Jain et al., 2015), the digital phenotype concept allows the expansion of the ability to diagnose medical conditions, redefining what we know about a disease expression.

In the very same year, considering the concept and implications related to digital phenotype, the term digital phenotyping was also proposed, defined as the "moment-by-moment quantification of the individual-level human phenotype in-situ using data from smartphones and other personal digital devices" (Torous, Kiang, Lorme, \& Onnela, 2016, p. 2). In this case, the authors clarified and operationalized the relationship of the stated concept and the potential to access information about people at the individual level and in the daily life (i.e., in-situ), using not only smartphones, but also any kind of technological gadget. A data collection in the digital phenotyping context is characterized by capturing people's behaviors, everyday experiences and interactions with the environment using both, active assessment (e.g., surveys) and passive assessment (e.g., number of calls, voice tone, or spatial trajectories based on GPS). Other concepts were also used in the mental health field and were mainly applied to assess health aspects (e.g., personality traits), but just rarely applied for psychiatric disorders (Carvalho \& Pianowski, 2017; Inkster, Stillwell, Kosinski, \& Jones, 2016). Example of this is the digital footprint term, referring to the information spontaneously generated (i.e., digital detritus; Venkatesh \& Christensen, 2017) depending on the person's activities on the internet (e.g. social network sites - SNS). In contrast, the digital phenotyping field seems to consider inherently psychiatric disorders aspects (Torous, Onnela, \& Keshavan, 2017), resembling the current tendency to the digitizing of the mind (Barrett, Steinhubl, Muse, \& Topol, 2017).

There are several practical applications for psychiatric disorders using the digital phenotyping propositions, although not always professedly. For instance: prediction of psychiatric conditions through smartphone usage behavior (e.g., ginger.io), platforms to personal data management (e.g., MyData) and for biomedical research use (e.g., Beiwe platform), digital health devices for mental and physical health tracking (e.g., simband from Samsung), public health intelligence systems for epidemic diseases monitoring (i.e. HealthMap), games for cognitive tracking and improvement (e.g., NeuroRacer), and even the settlement of specialized laboratories to digital phenotyping researches and related topics (e.g., Onnela Lab from Harvard School of Public Health). 
Corroborating the digital phenotyping literature, we argue in favor of using the data generated from the human interface with technology in mental health, essentially its application on particular diagnostic categories in psychiatry. Regardless the recognition of the wide practical possibility in the use of digital phenotyping in general psychiatry's pursuit (Torous, Firth, Mueller, Onnela, \& Baker, 2017; Torous, Onnela, et al., 2017; Torous et al., 2017), there is still little amount of studies addressing psychiatric disorders from this perspective (e.g., Torous et al., 2017; Ben-Zeev et al., 2017), probably due to its relatively recentness. Our focus is on the feasible use of digital phenotyping for one nosological category, personality disorder (PD). In other words, our scope is to bring forward a brandnew topic in the mental health field, digital phenotyping, particularly regarding possibilities and difficulties to applying this field to personality disorders. From our knowledge, no scientific publication was released, until the present moment, discussing applications, implications and presumable challenges in harnessing digital phenotyping data for PD diagnosis. Nevertheless, there is an expressive group of published studies (e.g. on digital footprints) that can be understood as initial research suggesting the potential of the directive application of the digital phenotyping for PD.

To support these claims, we performed a non-systematic literature search using Google Scholar primarily, as there are studies demonstrating its search capabilities as a single database (Gehanno, Rollin, \& Darmoni, 2013; Winter, Zadpoor, \& Dodou, 2014; Shariff et al., 2013). Moreover, the search was supplemented by forward and backward citation, and manual exploration of references.

\subsection{Digital phenotyping and personality disorders: applications, implications, and challenges}

PDs can be described as maladaptive extremes of healthy personality patterns, resulting from predisposing temperaments and stressful circumstances (Oldham, 2017). These conditions are characterized by impairments regarding self (e.g., self-identity) and interpersonal functioning (e.g., empathy capacity) (Skodol, 2012), and are specifically composed by pathological traits, considered as maladaptive variants of personality traits, implying substantial impairment to the individual in several areas of his life (American Psychiatric Association, 2013; Millon, 2016). 
Applications of digital phenotyping for PD depend on published studies, forming an initial framework based on empirical evidences. Although there are apparently no empirical studies covering PD specifically in the context of digital phenotypes, there are findings that may provide initial support for the field. For instance, studies investigating the relationship of Facebook self-promoting and anti-social behaviors on SNS with narcissism and anti-social pathological traits (Carpenter, 2012); correlations of self-posting behavior with narcissism and psychopathy traits (McCain et al., 2016); predictive statistical model development to psychopathy traits prediction based on Twitter observable behavior (Preotiuc-Pietro, Carpenter, Giorgi, \& Ungar, 2016); relationship between self-promoting behavior in Instagram and narcissism pathological traits (Moon, Lee, Lee, Choi, \& Sung, 2016). Moreover, there is also systematic reviews and meta-analytic studies (Carvalho \& Pianowski, 2017; Gnambs \& Appel, 2017; Liu \& Baumeister, 2016) suggesting narcissism as the most recurrent trait in researches. Two of the reviews (Gnambs \& Appel, 2017; Liu \& Baumeister, 2016) used all sorts of data (i.e., passive data and data dependent on the participant, specifically, self-reported data) on narcissism and social networking behavior (even self-reported), and in another (Carvalho \& Pianowski, 2017), the authors considered only data based on information that can be extracted from the internet without the users (i.e., passive data). In both cases, the researchers found the strongest relationships between narcissism traits and the number of friends in the SNS. In other words, associations were observed when collecting data through self-reported data and passive data. Given the benefits in using the latter, this evidence suggests the usability of passive data for the assessment of personality traits. We highlight that studies in this field are, in general, in the exploratory ground, reason why third variables, as moderator variables, are not usually considered.

Through the digital phenotype lens, the use of technology in accessing new sources of information may surpass what the traditional psychiatry already provides. Consider a patient with clinically diagnosed borderline PD. Regarding the core of this disorder (i.e., mood instability, impulsivity, risk taking behavior and self-mutilative tendency), using a smartphone data collection in such a patient would allow to find out behavioral data, such as dependent behavior in posting (text and pictures) pattern through SNS, erratic or exaggerated patterns of sending and responding messages/calls, risk taking behavior tracked through GPS, and even impulsivity based on physiological data (e.g., heart rate and skin conductance). 
From the ripening of the area, that is, from directive applications of digital phenotyping to assessment and diagnosis of PD, a range of beneficial implications should be observed. The overall benefits from using digital phenotyping in psychiatry has been discussed previously (Jain et al., 2015; Onnela \& Rauch, 2016), and can probably be applied for any disorder, including PD. Among the major advantages, the following must be stressed: access to a virtually infinite amount of information (e.g., through SNS; using specific digital health devices, based on technology from smartphones, such as GPS or camera), which may lead to determine new dysfunctional patterns of clinical groups (e.g., adding or refining the criteria of narcissistic PD) or even to establish new pathological disorders (e.g., re-include some PD excluded from the current manuals, for instance, dependent PD), as well as to determine currently unknown risk groups (e.g., people posting in several SNSs and using specific words in the posts); access to an unprecedented number of people, potentially increasing the access to care; fast, inexpensive, ecological (i.e., in-situ) and continuous data collection; access to information regardless of the person (i.e., passive data, not time consuming and does not implying user-bias), apart from the possibility of accessing type of information (e.g., GPS, voice tone) not possible by other means; communication of collected data with several other relevant health information, such as genetic information and laboratory tests; possibility of establishing a psychiatric (conceptual) model based mostly on prediction (i.e., surveillance and early detection) than based on emergency care, allowing the identification of symptoms before the expression of the traditional phenotypic. Early detection of PDs, probably regarding secondary prevention, is related to a better prognostic, although a poor prognostic is generally expected for these conditions (Paris, 2015). Ultimately, all benefits listed refer to the possibility of improvement in interventions. For instance, individual trajectories tracked through GPS can help determining high risk patterns, allowing the investigation of changes in individual trajectories (e.g., decrease in the number of trajectories per day, increase in the number of times the individual goes to specific stores). Thereby, the devices themselves can be used as an intervention (e.g., apps for behavioral tasks), a complement to traditional interventions (e.g., Hird, Ghosh, \& Kitano, 2016).

Furthermore, one of the main issues on PDs, current and controversial, concerns to the very existence of some of these disorders (see the PDs alternative model; American Psychiatric Association, 2013). A solution for this issue has been 
sought for decades, and also includes doubts on the criteria composing these disorders and how they should be grouped together. There is also a recent attempt on reviewing the traditional nosology (Kotov et al., 2017). Using digital phenotyping proposal, as real-time data collection through smartphone passive data, may facilitate to address these questions, helping to determine empirical dysfunctional patterns and/or to establish new pathological patterns.

As typically occurs in emerging fields, there is a lot to do before the digital phenotyping perspective will be completely adopted and applied to psychiatry (Jain et al., 2015; Torous et al., 2016; Venkatesh \& Christensen, 2017; Onnela \& Rauch, 2016) and, more specifically, for PD diagnosis. The first challenge is to make up multiprofessional work teams qualified to implement the technologies required for data collection; then, develop integrative (for both, Apple and Android systems) and open access platforms to storage, group, and share data. As discussed in a paragraph forward, norms for using these platforms (e.g., what platforms can be used by professionals and what platforms can be used by patients) must be addressed in a systematic way. Once the devices and platforms are operating, there will be a need of an investigation regarding behavioral and physiological variables relevant for predicting pathological personality traits converted into raw digital data (and the best data analysis to deal with these raw material); in other words, the pattern of pathological functioning in the virtual environment of the various PDs must be sought and established. Knowing pathological patterns in the virtual environment and based on physiological data will also enable the comparison of these patterns with people baselines, allowing an early prediction of psychiatric disorders. Baseline comparison with current patterns can be applied through different developmental stages (e.g., comparing the individual's behavior in adolescence with behavior in the adulthood), or applied as comparison of periods in which the individual is not reporting impairment from pathological traits with periods when impairment is reported (considering that pathological traits are not inflexibly stable, see Hopwood \& Bleidorn, 2018).

The application and recognition of these patterns will also depend on the verification of the optimal analyzes for raw data, including deep learning and machine learning algorithms (e.g., Saeb, Cybulski, Kording, \& Mohr, 2017). As important as the benefits, the process of establishing this new field, as well as the productions arising from its practical application, must be permeated by clear 
ethical guidelines on how information can and should be used (e.g., privacy and responsibility on data), a topic already in discussion (e.g., Torous \& Nebeker, 2017; Torous \& Roberts, 2017). Given the operational lack of boundary in the digital era, the concerns with ethical contours is defied by the amplitude and openness of the virtual environment (Venkatesh \& Christensen, 2017; Torous, Onnela et al., 2017; Onnela \& Rauch, 2016; Torous \& Nebeker, 2017). The traditional ethical aspects (such as confidentiality, consent and security) have challenged scientists to discuss broader impacts of the emergent integration of digital data/tools and health practices, which has compelling steps beyond the usual ones (see Torous \& Nebeker, 2017).

\section{Conclusions}

]At this time, the initial expectations, and the (yet) small body of evidences, are that the digital phenotyping will bring improvements for assessment and diagnostic of various conditions in mental health, as in PD, and will broaden the concepts of psychopathological diseases and the very psychopathological functioning itself (e.g., helping to determine the taxonomic nature of the disorders; Wiederhold, 2016; Torous et al., 2016; Onnela \& Rauch, 2016). Affirming the digital phenotyping will resolve the persistent difficulty in mental health, i.e., the quantification of disease phenotypes, is, perhaps, not an overstatement. However, it is too early to assert how far the applications will actually be viable and increase the knowledge already established. Moreover, as explained before, several obstacles still need to be addressed. Accordingly, once obstacles have been overcome and ethical guidelines are well established, researchers will need to be prepared to deal with the practical insertion of digital phenotyping into the routine of mental health professionals (e.g., Mohr, Weingardt, Reddy, \& Schueller, 2017), helping in figuring out how to integrate these data into clinical practice.

\section{References}

American Psychiatric Association (2013). Diagnostic and statistical manual of mental disorders(DSM-5) (5 $5^{\text {th }}$ Edition). Washington, DC: American Psychiatry Association.

Barrett, P. M., Steinhubl, S. R., Muse, E. D., \& Topol, E. J. (2017). Digitising the mind. The Lancet, 13(389): 1877. doi:10.1016/S0140-6736(17)31218-7 
Ben-Zeev, D., Brian, R., Wang, R., Wang, W., Campbell, A. T., Aung, M. S. H. ... Scherer, E. A. (2017). CrossCheck: Integrating self-report, behavioral sensing, and smartphone use to identify digital indicators of psychotic relapse. Psychiatric Rehabilitation, 40(3), 266-275. doi:10.1037/prjoooo243

Carpenter, C. J. (2012). Narcissism on Facebook: Self-promotional and anti-social behavior. Personality and individual differences, 52(4), 482-486. doi:10.1016/j. paid.2011.11.011

Carvalho L. F., \& Pianowski, G. (2017). Pathological personality traits assessment using Facebook: Systematic review and meta-analyses. Computers in Human Behavior, 71, 307-317. doi:10.1016/j.chb.2017.01.061

Gehanno, J. F., Rollin, L., \& Darmoni, S. (2013). Is the coverage of Google Scholar enough to be used alone for systematic reviews. BMC Med Inform Decis Mak, 9, 13-17. doi:10.1186/1472-6947-13-7

Gnambs, T., \& Appel, M. (2017). Narcissism and social networking behavior: A metaanalysis. Journal of Personality, 86(2), 200-212. doi: 10.1111/jopy.12305

Hird, N., Ghosh, S., \& Kitano, H. (2016). Digital health revolution: Perfect storm or perfect opportunity for pharmaceutical R\&D? Drug discovery today, 21(6), 900-911. doi:10.1016/j.drudis.2016.01.010

Hopwood, C. J., \& Bleidorn, W. (2018). Stability and change in personality and personality disorders. Curr Opin Psychol, 21, 6-10. doi:10.1016/j.copsyc.2017.08.034

Inkster, B., Stillwell, D., Kosinski, M., \& Jones, P. (2016). A decade into Facebook: Where is psychiatry in the digital age? The Lancet Psychiatry, 3(11), 1087-1090.

Jain, S. H., Powers, B. W., Hawkins, J. B., \& Brownstein, J. S. (2015). The digital phenotype. Nature biotechnology, 33(5), 462-463. doi:10.1038/nbt.3223

Kotov, R., Krueger, R. F., Watson, D., Achenbach, T. M., Althoff, R. R., Bagby, R.M. ... Zimmerman, M. (2017). The Hierarchical Taxonomy of Psychopathology (HiTOP): A dimensional alternative to traditional nosologies. Journal of abnormal psychology, 126(4), 454-477. doi:10.1037/abnoooo258

Liu, D., \& Baumeister, R. F. (2016). Social networking online and personality of self-worth: A meta-analysis. Journal of Research in Personality, 64, 79-89. doi:10.1016/j. jrp.2016.06.024 
McCain, J. L., Borg, Z. G., Rothenberg, A. H., Churillo, K. M., Weiler, P., \& Campbell. W. K. (2016). Personality and selfies: Narcissism and the Dark Triad. Computers in Human Behavior, 64, 126-133. doi:10.1016/j.chb.2016.06.050

Millon, T. (2016). What is a personality disorder? Journal of personality disorders, 30(3), 289-306.

Mohr, D. C., Weingardt, K. R., Reddy, M., Schueller, S. M. (2017). Three problems with current digital mental health research ... and three things we can do about them. Psychiatric Services, 68(5), 427-429. doi:10.1176/appi.ps.201600541

Moon, J. H., Lee, E., Lee, J. A., Choi, T. R., \& Sung, Y. (2016). The role of narcissism in self-promotion on Instagram. Personality and Individual Differences, 101, 22-25. doi:10.1016/j.paid.2016.05.042

Oldham, J. M. (2017). DSM Models of Personality Disorders. Curr Opin Psychol, 21, 86-88.

Onnela, J. P., \& Rauch, S. L. (2016). Harnessing smartphone-based digital phenotyping to enhance behavioral and mental health. Neuropsychopharmacology: Official publication of the American College of Neuropsychopharmacology, 41(7), 1691. doi:10.1038/ npp.2016.7

Paris, J. A. (2015). A concise guide to personality disorders. Washington, DC: American Psychiatric Association.

Preotiuc-Pietro, D., Carpenter, J., Giorgi, S., \& Ungar, L. (2016). Studying the dark triad of personality through Twitter behavior. In Proceedings of the 25th ACM International on Conference on Information and Knowledge Management, 761-770.

Saeb, S., Cybulski, T. R., Kording, K. P., \& Mohr, D. C. (2017). Scalable passive sleep monitoring using mobile phones: Opportunities and obstacles. Journal of Medical Internet Research, 19(4), e118. doi:10.2196/jmir.6821

Shariff, S. Z., Bejaimal, S. A., Sontrop, J. M., lansavichus, A. V., Haynes, R. B., Weir, M. A., \& Garg, A. X. (2013). Retrieving clinical evidence: a comparison of PubMed and Google Scholar for quick clinical searches. J Med Internet Res, 15(8), e164. doi:10.2196/jmir.2624

Skodol, A. E. (2012). Personality Disorders in DSM-5. Annu Rev Clin Psychol, 8(1), 317-344.

Torous, J., \& Nebeker, C. (2017) Navigating ethics in the digital age: Introducing Connected and Open Research Ethics (CORE), a tool for researchers and institutional review boards. Journal of Medical Internet Research, 19(2), e38. doi:10.2196/jmir.6793 
Torous, J., Firth, J., Mueller, N., Onnela, J. P., \& Baker, J. T. (2017). Methodology and Reporting of Mobile Heath and Smartphone Application Studies for Schizophrenia. Harvard Review of Psychiatry, 25(3), 146-154. doi:10.1097/HRP.0000000000000133

Torous, J., Kiang, M. V., Lorme, J., \& Onnela, J.P. (2016). New tools for new research in psychiatry: A scalable and customizable platform to empower data driven smartphone research. JMIR Mental Health, 3(2), e16. doi:10.2196/mental.5165

Torous, J., Onnela, J. P., \& Keshavan, M. (2017). New dimensions and new tools to realize the potential of RDoC: Digital phenotyping via smartphones and connected devices. Translational Psychiatry, 7(3), e1053. doi:10.1038/tp.2017.25

Torous, J., \& Roberts, L. W. (2017). Needed innovation in digital health and smartphone applications for mental health transparency and trust. JAMA Psychiatry, 74(5), 437-438. doi:10.1001/jamapsychiatry.2017.0262

Venkatesh, S., \& Christensen, H. (2017). Using life's digital detritus to feed discovery. The lancet psychiatry, 4(3), 181. doi:10.1016/S2215-0366(16)30351-0

Wiederhold, B. K. (2016). Using your digital phenotype to improve your mental health. Cyberpsychology, Behavior, and Social Networking, 19(7), 419. doi:10.1089/ cyber.2016.29039.bkw

Winter, J. C. F., Zadpoor, A. A., \& Dodou, D. (2014). The expansion of Google Scholar versus Web of Science: A longitudinal study. Scientometrics, 98(2), 1547-1565. doi:10.1007/s11192-013-1089-2

\section{Authors notes}

Lucas de Francisco Carvalho, Department of Psychology, São Francisco University (USF); Giselle Pianowski, Department of Psychology, São Francisco University (USF). Correspondence concerning this article should be addressed to Lucas de Francisco Carvalho, Rua Alexandre Rodrigues Barbosa, 45, Centro, Itatiba, São Paulo, SP, Brazil. CEP: $13251-900$

E-mail: lucas@labape.com.br 